\section{Estrategias metodológicas para la enseñanza de la coherencia textual: calidad de la información, desde una nueva perspectiva}

Msc. Nayiri Fonseca Sevilla Msc. Thema Susana Muñoz Tinoco Msc. Rosa María Aguirre Bermúdez Msc María Engracia López Talavera Msc. Cándida Rosa Quintanilla Membreño Msc Felipe Heriberto Orozco López (c) UNAN-Managua Recibido: mayo 2016 Aprobado: junio 2016

\title{
RESUMEN
}

El objetivo central de esta investigación es contribuir a mejorar el proceso enseñanza- aprendizaje de la expresión escrita, y ofrecer al profesorado una visión más clara del empleo de métodos con enfoque comunicativo que permitan clases activas y participativas, en las cuales se pongan en práctica las macrohabilidades del lenguaje, necesarias para una efectiva comunicación. En ella se analizan los principales problemas de coherencia textual: calidad de la información, que presentan los escritos diagnósticos de los estudiantes de primer año de la carrera de Lengua y Literatura Hispánicas, del curso regular y de profesionalización del Departamento de Español. Las dificultades detectadas sirvieron como punto de referencia para la elaboración y ejecución de un proyecto didáctico que incidiera positivamente en la superación de las mismas y de esta manera potenciar los recursos comunicativos y expresivos que garanticen a los estudiantes un eficiente desenvolvimiento académico, profesional y social. Los resultados obtenidos fueron positivos y a partir de los mismos se puede afirmar que es posible mejorar los textos elaborados a través de la realización de escritos consensuados e interesantes, mediante un proceso recursivo que involucre los subprocesos de planificación, textualización, revisión y corrección, en los que participen activamente maestros/as y estudiantes y además se posibilite el acceso a materiales teóricos, pautas de orientación, guías de evaluación y autoevalución que faciliten el éxito de la tarea a realizar.

\section{Introducción}

Los estudiantes de los diferentes niveles de educación primaria, secundaria y superior presentan dificultades en la redacción de sus textos: ideas incompletas, imprecisión y pobreza léxica, repetición de palabras e ideas, problemas ortográficos, alteración de la sintaxis, entre otras. Se considera que los problemas antes mencionados se deben principalmente a la atención inadecuada del proceso de enseñanza - aprendizaje de la lengua y al predominio del aprendizaje gramatical.

Como docentes preocupados por las cuestiones relativas a la enseñanza de la lengua y conscientes de los problemas de los alumnos, con esta investigación se pretende contribuir a mejorar el proceso enseñanza aprendizaje de la expresión escrita. Para lograr este objetivo se realizó una diagnosis donde se valoraron problemas de coherencia textual relacionados con la calidad de la información: ideas incompletas o subdesarrolladas, varias ideas en un párrafo y relación entre las mismas, problemas de concordancia, repetición innecesaria de palabras, frases e ideas, léxico inadecuada al tema, contexto comunicativo, tipo de repceptor e intenciones del autor, falta de claridad en las ideas y coherencia textual en la redacción de textos expositivos. A partir de éstas se elaboró y validó un proyecto de escritura que contribuyera a mejorar las dificultades detectadas.. 


\section{Metodología}

La presente investigación se inserta en el paradigma cualitativo, el cual permite al investigador observar e identificar los problemas más frecuentes que se presentan en el aula de clase, igualmente facilita la toma de decisiones y la evaluación de aspectos fundamentales del proceso de enseñanza - aprendizaje.

La población en estudio se conformó con los alumnos de tres grupos de primer año de la carrera de Lengua y Literatura Hispánicas, dos de cursos de profesionalización y uno de regulares, para un total de 84 alumnos y alumnas. Los métodos empleados fueron análisis, síntesis, observación participante, encuesta a los estudiantes, y entrevista al profesor colaborador, realizadas al concluir la secuencia didáctica. Entre los instrumentos empleados para la recolección de los datos se destacan las pruebas documentales, grabadora y video.

Los resultados obtenidos del análisis de la prueba diagnóstica, bosquejos y textos expositivos elaborados por los estudiantes, encuesta aplicada a los mismos y la entrevista realizada al docente colaborador, fueron interpretados y contrastados, a través del proceso de TRIANGULACIÓN.

\section{Análisis de datos}

El cuadro siguiente resume los problemas de coherencia textual encontrados en los escritos diagnósticos de los tres grupos de estudiantes seleccionados.

\begin{tabular}{|c|c|c|c|c|c|}
\hline & \multicolumn{3}{|c|}{ Grupos } & \multirow[b]{2}{*}{ OTAL } & \multirow[t]{2}{*}{$\%$} \\
\hline Variables & $\mathbf{A B}$ & & CT & & \\
\hline [...] Ideas incompletas subdesarrolladas & 16 & 171 & 5 & 48 & $57 \%$ \\
\hline // Varias ideas en un párrafo & 5 & 6 & 16 & 27 & $32 \%$ \\
\hline U Problemas de concordancia & 12 & 10 & 16 & 38 & $45 \%$ \\
\hline A-C Relación antecedente - consecuente & 0 & 8 & 7 & 15 & $18 \%$ \\
\hline$\longleftrightarrow$ Relación entre las ideas del párrafo & 7 & 7 & 7 & 21 & $25 \%$ \\
\hline Relación entre párrafos & 2 & 9 & 6 & 17 & $20 \%$ \\
\hline$X$ Empleo de información irrelevante & 1 & 1 & 7 & 9 & $11 \%$ \\
\hline - + Pproblemas de ubicación jerárquica de las ideas & 0 & 2 & 4 & 6 & $7 \%$ \\
\hline Repeticiones innecesarias de palabras, frases e ideas & 15 & 15 & 21 & 51 & $61 \%$ \\
\hline $\begin{array}{l}\text { ( ) Léxico inadecuado al tema, contexto comunicativo, } \\
\text { tipo de receptor e intenciones del autor }\end{array}$ & 13 & 11 & 13 & 37 & $44 \%$ \\
\hline ¿? Falta de claridad en las ideas & 8 & 19 & 17 & 44 & $52 \%$ \\
\hline C-G Problemas de coherencia global & 9 & 19 & 15 & 43 & $51 \%$ \\
\hline Estudiantes & 26 & 22 & 36 & 84 & \\
\hline
\end{tabular}

*A, B, C : Grupos de estudiantes que cometieron errores.

* Variables: Equivalen a errores cometidos por los estudiantes.

* El porcentaje de cada variable se obtuvo de dividir el total de estudiantes que cometieron el error entre el número de estudiantes que realizaron la prueba diagnóstica. 
El número de estudiantes que realizaron el texto fue de ochenta y cuatro (84), de éstos, cincuenta y uno (51), correspondiente al $61 \%$ del universo en estudio incurrieron en errores de repetición innecesaria de palabras, frases e ideas, lo que evidencia que más de la mitad de los alumnos de los grupos $A, B, Y C$ tienen problemas de pobreza léxica y falta de dominio del tema. Otro porcentaje significativo es el de la variable ideas incompletas o subdesarrolladas, con cuarenta y ocho (48) estudiantes, para un $57 \%$. Este dato refleja que los estudiantes no están conscientes de la necesidad de expresar sus ideas en forma completa y clara.

Igualmente, se puede apreciar en el análisis que las variables: falta de claridad en las ideas, y problemas de coherencia global, aparecen reflejadas en el cuadro con un $52 \%$ y $51 \%$ respectivamente, lo que demuestra que es imposible separarlas de las variables en estudio, ya que para lograr la coherencia en un texto es necesario considerar una serie de recursos de índole textual, sin los cuales sería imposible lograr una adecuada comunicación con nuestros/as lectores/as.

En el cuadro se refleja que los estudiantes presentan serios problemas de concordancia, representados por el $45 \%$. También se encontraron en los escritos, empleo de léxico inadecuado al tema, contexto comunicativo, tipo de receptor e intenciones del autor, lo cual oscurece las ideas que se pretenden comunicar. En menor porcentaje, 36\%, los estudiantes presentan más de una idea en el párrafo, falta de relación entre las ideas del mismo, 25\%, y entre párrafos, 20\%. Lo antes expuesto evidencia el desconocimiento que tienen los estudiantes sobre la importancia de atender las características del párrafo, al escribir sus textos, y de esta manera lograr un escrito coherente que responda a las exigencias de la lengua escrita y a las necesidades de comunicación de los seres humanos.

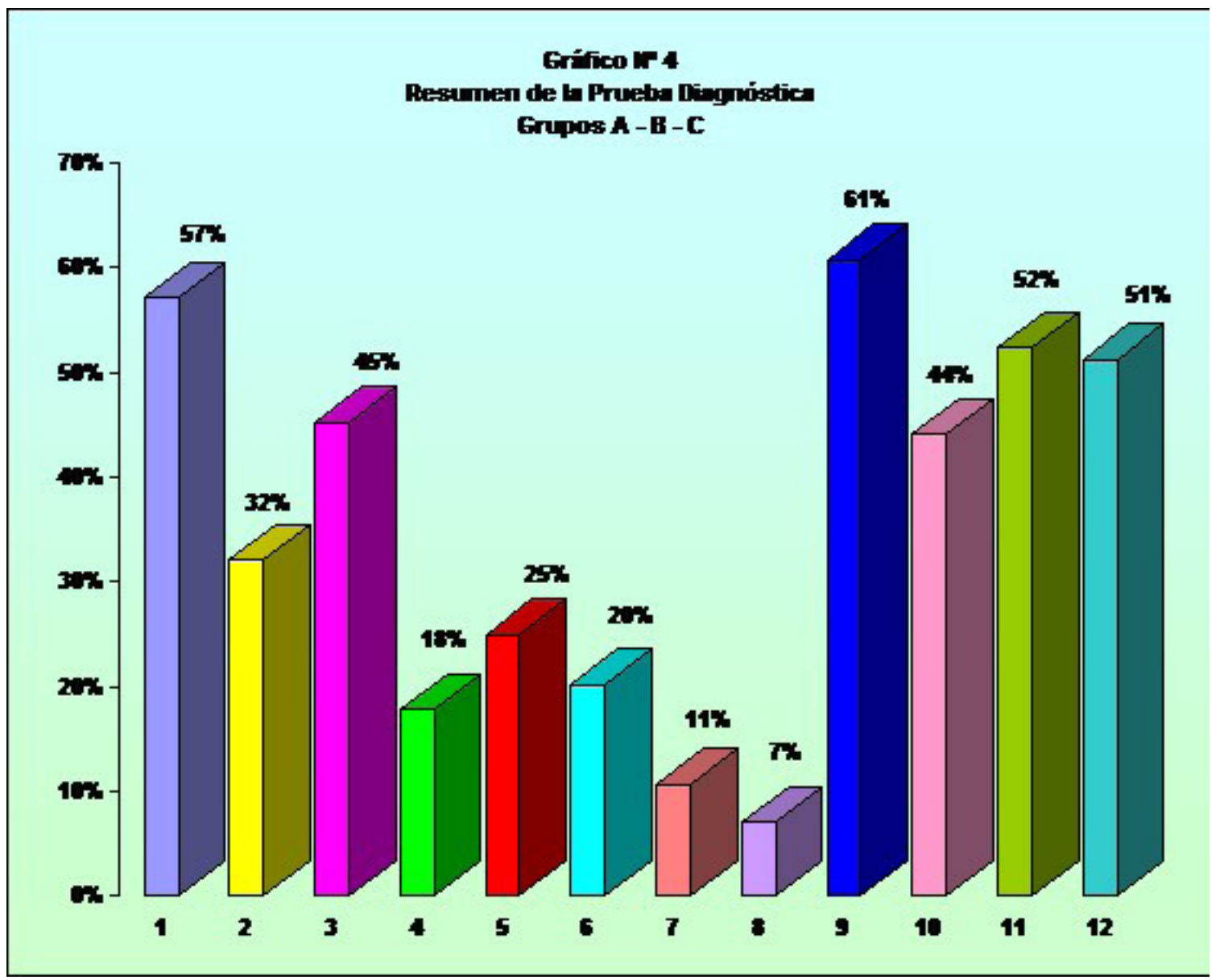


1 Ideas incompletas o subdesarrolladas

2 Varias ideas en un párrafo

3 Problemas de concordancia

4 Relación antecedente - consecuente

5 Relación entre las ideas del párrafo

6 Relación entre párrafos

7 Empleo de información irrelevante
8 Problemas de ubicación jerárquica de las ideas

9 Repeticiones innecesarias de palabras, frases e ideas

10 Léxico inadecuado al tema, contexto comunicativo, tipo de receptor e intenciones del autor

11 i ? Falta de claridad en las ideas

12 C-G Problemas de coherencia global

\section{Análisis de las versiones de los esquemas elaborados por los estudiantes seleccionados para el estudio}

A continuación presentamos el análisis de las diversas versiones de los esquemas elaborados por los estudiantes, antes de la elaboración del texto expositivo. Es necesario destacar que "el esquema presenta un orden y una jerarquía. El orden de las ideas en el esquema se repetirá en el texto (salvo en el caso de cambios eventuales introducidos en el proceso de la redacción)," (Serafini, 1998:91), de allí la importancia de que los estudiantes elaboren un plan previo a la textualización, a fin de que les guíe el proceso de escritura.

Los esquemas que se presentan a continuación pertenecen a la pareja seleccionada del grupo $\mathrm{A}$, en la cual está integrado el estudiante $\mathrm{N}^{\circ} 18$, objeto de estudio en la prueba diagnóstica. A este grupo se dio el seguimiento requerido para poder comprobar los avances obtenidos, las dificultades a las que se enfrentaron durante el proceso de elaboración del texto y los recursos didácticos utilizados para la superación de los mismos.

\section{Análisis de la versión $\mathbf{N}^{\circ} 1$ del esquema.}

\section{Esquema}

¿Qué sucede en la mujer después de los cuarenta?

I. Introducción

A. Menopausia

II. Desarrollo.

B. Efectos de la deficiencia de estrógenos.

1- Cambios en el ciclo y flujo menstrual.

2- Bochornos y sudores nocturnos

3- Atrofia urogenital

C. Consecuencias a largo plazo

1- Evaluación de los riesgos

2- Osteoporosis

3- Enfermedad cardiovascular

4- Prevenciones

D. Sexualidad

1. Síntomas de la deficiencia hormonal
a. En el organismo
b. Autoestima-
c. Pareja 
III. Conclusión

E. Tratamiento

1- Terapia de reemplazo hormonal

2- Efectos y riesgos

3- Bienestar general

El esquema comienza con una interrogante incompleta, en ella no aparecen elementos que aclaren a qué tipo de cambios se referirán en el desarrollo del texto, además falta la palabra años para completar el sentido.

En los números romanos que indican las ideas de primer orden escribieron las partes del texto expositivo: introducción, desarrollo y conclusión, que corresponden a la estructura del mismo. Las ideas de segundo orden, en el esquema, no siguieron la secuencia convencional correspondiente ya que las organizaron sin considerar las ideas cabezales de cada acápite. Por ejemplo en el número romano II comenzaron con la letra B en lugar de A. De lo anterior, se deduce que los estudiantes a pesar de que estudiaron las características del esquema, analizaron modelos, etc. no lograron interiorizar la estructura del mismo, ni tomar conciencia de la importancia de la organización de éste para la textualización.

En los números romanos I y III solamente aparece una idea de segundo orden respectivamente, $y$ en un esquema debidamente elaborado no debe existir una idea $A \sin B$. En el romano II, letra $D$ aparece el número arábigo 1 con su respectivo desglose $a, b$ y $c$, pero no existe un número 2 para introducir otra idea de tercer orden que amplíe el posterior desarrollo del párrafo.

Los estudiantes hicieron esfuerzos por organizar jerárquicamente las ideas del esquema. Primero caracterizaron, de manera general, la menopausia, seguidamente hicieron referencia a los efectos que ésta produce en el organismo de la mujer y finalmente concluyeron con la referencia al tratamiento necesario para disminuir los efectos y riesgos de la misma.

Las ideas del esquema no están completas. Las de primer orden, como se señaló anteriormente, hacen alusión a la estructura del texto expositivo, las de segundo orden también están incompletas, ejemplos: Menopausia, no aclaran si van a conceptualizarla y/o caracterizarla. Efectos de la deficiencia de estrógeno, no se señala quién será la que sufrirá los efectos de la falta de estrógenos. Consecuencias a largo plazo, no se expresa quien recibirá las consecuencias.

Siguiendo el orden del análisis, se puede observar que el término Sexualidad no corresponde a las ideas de segundo orden, sino que a las de tercer orden y en su lugar debería estar síntomas de la deficiencia hormonal, que es una idea más amplia y abarca el aspecto de la sexualidad. Finalmente aparece la palabra Tratamiento, que tampoco indica el tipo de tratamiento ni para quién será. De esta idea de primer orden se desprenden: Terapia de reemplazo hormonal, efectos y riesgos y Bienestar general, aspectos que deben derivarse del empleo de la terapia de reemplazo y no colocarse como ideas del mismo orden.

Obviamente los estudiantes que conforman esta pareja, no están claros del orden que deben tener las ideas en el esquema, ni de la importancia de las mismas para la elaboración del texto. Todo lo anterior se origina, desde luego, por una enseñanza- aprendizaje débil de la expresión escrita, sin una visión de proceso recursivo en el cual cada fase juega un papel fundamental. 
Dentro de estas etapas está la planificación la cual permite al escritor organizar sus ideas, pensar en el receptor de su texto, los objetivos y el nivel de lengua que deberá emplear para que el escrito sea debidamente recepcionado por los posibles lectores del mismo.

\section{Análisis de la versión $\mathbf{N}^{\circ} \mathbf{2}$ del esquema}

En la versión $\mathrm{N}^{\circ} 2$ del esquema no se observaron cambios sustanciales, las ideas se conservaron como en el primero, únicamente hubo un ligero progreso en el desglose del punto Il del esquema, correspondiente al desarrollo, con excepción del punto $\mathrm{C}$ del mismo, en el cual aparece una idea de tercer orden únicamente.

II. Desarrollo:

A. Efectos de la deficiencia de estrógenos.

1 - Cambios en el ciclo y flujo menstrual.

2- Bochornos y sudores nocturnos.

3- Atrofia urogenital.

B. Consecuencias a largo plazo.

1- Osteoporosis.

2- Enfermedades Cardiovasculares

3- Prevenciones.

C. Sexualidad:

1- Síntoma de la deficiencia hormonal

a- En el organismo.

b- Autoestima.

c- En la pareja.

\section{Análisis de la versión $\mathbf{N}^{\circ} 3$ del esquema.}

I. La menopausia etapa de cambios en las mujeres mayores de cuarenta años.

A. Conceptualización.

B. Características.

II. Consecuencias que provoca la menopausia en la mujer, después de los cuarenta años de edad.

A. Efectos físicos:

1- Pérdida de estrógeno hormonal.

2- Deterioro en la función hormonal.

3- Bochornos y sudores nocturnos.

4- Atrofia Urogenital.

5- Osteoporosis.

6- Enfermedades cardiovasculares.

B. Efectos sicológicos:

1- Disminución del deseo sexual.

2- Baja autoestima.

3- Conflictos en la pareja.

4- Aislamiento Social.

5- Pérdida de la memoria.

6- Depresión. 
III. Tratamiento para reducir los síntomas en el período de la menopausia.

A. Terapia de reemplazo hormonal en la etapa de la Menopausia.

B. Tipos de tratamiento de reemplazo hormonal.

1 - Tabletas vía oral.

2- Parches transdérmicos.

3- Crema vaginal.

4- Inyecciones.

5- Implantes.

C. Efectos positivos de la terapia de reemplazo hormonal.

1- Reducción de molestias físicas.

2- Recuperación de su autoestima.

3- Mejora en la relación de pareja.

4- Preservación de la salud.

5- Bienestar general.

D. Efectos negativos de la terapia de reemplazo hormonal.

1- Cefalea.

2- Aumento de peso.

3- Dolor con la palpación mamaria.

4- Menorragia

5- Alteraciones cutáneas.

En el esquema $N^{\circ} 3$ puede observarse un avance sustancial, pues los estudiantes realizaron un mejor desglose del tema en las ideas troncales I, II y III, en las de segundo y tercer orden. Además lograron superar los problemas de ideas incompletas. Lo anterior, se logró por la disposición de los estudiantes para revisar y corregir su esquema y por el constante proceso de andamiaje de los docente pues, " a menudo las personas somos capaces de resolver problemas o de efectuar aprendizajes nuevos cuando contamos con la ayuda de nuestros semejantes, pero no conseguimos abordar con éxito estas mismas tareas cuando disponemos únicamente de nuestros propios medios." (Coll y Solé, 1990:351).

\section{Análisis de los textos expositivos elaborados por la pareja seleccionada en el grupo A}

El análisis de los textos elaborados por los estudiantes se dividió en tres aspectos: primeramente se realizó una revisión general de los mismos, después se identificaron los problemas de coherencia textual: calidad de la información, presentes en los escritos y finalmente se establecieron comparaciones entre ellos.

El primer texto está integrado por trece (13) párrafos, extensos en algunos casos. El segundo por diecinueve (19), muy breves, y el tercero por trece (13), algunos de ellos cortos. En relación con el título éste se conservó en los tres textos, ¿Qué sucede a la mujer después de los cuarenta? A pesar de que en el primer texto se orientó a los estudiantes completar la idea, con las palabras: problemas, sicológicos, fisiológicos, padecen y años. ¿ Qué tipos de problemas sicológicos y fisiológicos padecen las mujeres después de los cuarenta años?

De los tres textos elaborados los dos primeros no se ajustaron exactamente a los esquemas, solamente en el tercero se observa una mayor relación entre el esquema y el texto. Lo anterior demuestra que los estudiantes comprendieron la importancia del bosquejo como guía para la textualización. Igualmente durante el proceso de escritura consultaron bibliografía, discutieron en parejas, atendieron las orientaciones del docente, revisaron y corrigieron sus textos. 
La estructura de los escritos elaborados se ajusta a las características del texto expositivo: Introducción, Desarrollo y Conclusión, lo que ayudó a los estudiantes interiorizar los principales rasgos de este tipo de texto y lograr un escrito coherente que permitiera una lectura ágil y mejor comprensión del mismo. Obviamente a lo largo del proceso los estudiantes realizaron esfuerzos para superar poco a poco algunas de las dificultades señaladas por sus compañeros o por el profesor/a.

A continuación se presentan ejemplos del comportamiento de cada una de las variables en estudio, tomadas de los textos elaborados por los estudiantes.

\section{Ideas incompletas y subdesarrolladas / Ejemplos.}

En relación con el problema de ideas incompletas o subdesarrolladas, se encontró:

\section{Primer texto. Ejemplo.}

Esta deficiencia también causa Atrofia Urogenital.

En este ejemplo la idea está incompleta porque no aclaran a qué tipo de deficiencia se refieren. Las ideas incompletas o subdesarrolladas afectan la claridad del escrito y por ende la coherencia del mismo, el texto debe constituir una unidad que debe ser percibida por el lector para lograr su comprensión total.

\section{Segundo texto. Ejemplo.}

La deficiencia de estrógenos también causa atrofia urogenital,[...].

En este texto los escritores aclaran que la deficiencia se debe a la falta de estrógenos.

\section{Tercer texto. Ejemplo.}

Otra consecuencia originada por la falta de estrógeno es la atrofia urogenital.

En el último texto cambian la palabra deficiencia por consecuencia y se aclara que la atrofia urogenital es originada por la falta de estrógeno. Si comparamos la idea expresada en el primero y en el tercero, claramente se observa un cambio significativo, porque en el último texto la idea está completa.

\section{Varias ideas en un párrafo y relación entre las ideas del mismo. Ejemplos: Primer texto. Ejemplo.}

[...] se ha comprobado que el reemplazo de estrógeno es altamente eficaz para reducir el riesgo de estas enfermedades, su médico le orientará el tratamiento adecuado.

Los estrógenos mantienen la integridad de los tejidos sexuales. En la menopausia el epitelio vaginal se adelgaza y adquiere un carácter alcalino, deja de producir glucógeno, se encoge y sufre con facilidad daños e infecciones. 
En el segundo párrafo del texto presentado se puede apreciar que los escritores iniciaron el mismo con una idea relacionada con la importancia de los estrógenos, la que debieron integrar en el anterior porque en él se aborda el mismo tema. La otra idea tiene que ver con aspectos específicos de la menopausia. En los textos 2 y 3 no se dieron problemas de este tipo. Se observa en estos dos un avance de parte de los estudiantes, y se debe principalmente a la puesta en práctica de la secuencia didáctica, donde se orientó la redacción de escrito expositivo a partir de un proceso.

\section{Problemas de concordancia. Ejemplos.}

Uno de los problemas de concordancia encontrado en los tres textos es el siguiente:

\section{Primer texto.}

Esta deficiencia también causa Atrofia Urogenital. Es cuando los tejidos de las vías urinarias y el tracto vaginal se vuelve más delgado, se encogen y se secan.

En este ejemplo el verbo vuelve y el adjetivo delgado deberían estar en plural para concordar con tejidos y con tracto vaginal.

Segundo texto. Ejemplo.

La deficiencia de estrógenos también causa atrofia urogenital, los tejidos de las vías urinarias y el tracto vaginal se vuelven más delgado, se encogen y se secan.

En este texto los escritores superaron el problema de concordancia con el verbo vuelven, sin embargo persiste en el adjetivo delgado.

\section{Tercer texto. Ejemplo.}

Otra consecuencia originada por la falta de estrógeno es la atrofia urogenital. Los tejidos de las vías urinarias y el tracto vaginal, se vuelven más delgados se encogen y se secan.

En el tercer texto los estudiantes superaron el problema de concordancia de número entre el adjetivo delgados, y el sustantivo tejidos el cual no había sido mejorado en el primero ni en el segundo texto.

\section{Repetición innecesaria de palabras, frases e ideas. Ejemplos.}

\section{Primer texto. Ejemplo.}

La osteoporosis es una enfermedad de huesos frágiles, cuando los huesos no reciben estrógeno su densidad disminuye y se fractura fácilmente, la pérdida de masa ósea suele ser rápida una vez que comienza la menopausia, [...].

En este texto los estudiantes repitieron dos veces la palabra huesos y además, en el mismo incluyeron masa ósea. 


\section{Segundo texto. Ejemplo.}

La osteoporosis es frecuente en esta etapa menopáusica debido a las alteraciones del metabolismo óseo asociados a la reducción de estrógenos.

\section{Tercer texto. Ejemplo.}

La Osteoporosis es frecuente en esta etapa debido a las alteraciones del metabolismo óseo producido por la reducción de estrógeno.

En el segundo y tercer texto omitieron la palabra huesos y en vez de masa ósea emplearon la frase metabolismo óseo. En cuanto a la repetición innecesaria de palabras, frases e ideas, a pesar de la tendencia general de los estudiantes a cometer este error, por la falta de hábitos de lectura, comprensión de las palabras, consulta en diccionarios, poca práctica en el uso de sinónimos, antónimos, y parónimos, en la redacción de los Textos Expositivos no se observó este problema con mucha frecuencia.

\section{Léxico inadecuado al tema, contexto comunicativo, tipo de receptor e in- temciones del autor.}

\section{Primer texto. Ejemplo.}

La menopausia es un acontecimiento único por la pérdida de la función ovárica y la falta de estrógeno.

En este ejemplo los escritores utilizaron inadecuadamente el término acontecimiento, éste significa: Suceso, acaecimiento, episodio, evento, hecho etc. por tanto no explicita la idea de período, etapa o fase que sería lo más adecuado en este contexto.

\section{Segundo texto. Ejemplo.}

La menopausia es la etapa de cambio en la mujer.

\section{Tercer texto. Ejemplo.}

La menopausia es una etapa de cambio en la mujer.

Como puede observarse en el segundo y tercer texto los estudiantes utilizaron la palabra etapa en lugar de acontecimiento, lo cual indica mayor precisión en el uso del término. Para que un texto sea comprensible es necesario elegir palabras precisas, variadas y adecuadas al tema que se trata, tipo de escrito y a los lectores. Una buena selección léxica es determinante para lograr un texto eficaz. La utilización de diccionarios durante el proceso de escritura es de gran utilidad para resolver dudas, buscar sinónimos, conocer los diversos significados y la escritura correcta de los términos. . 


\section{Conclusiones}

Las conclusiones presentadas a continuación son producto del análisis de los escritos diagnósticos, esquemas, textos elaborados durante el proyecto didáctico, opiniones de los observadoras participantes, docente colaborador y estudiantes, en relación con la coherencia textual: calidad de la información.

10.1 Los textos diagnósticos de los estudiantes de Lengua y Literatura Hispánica de lo cursos regulares y de profesionalización presentan los siguientes problemas de coherencia textual, calidad de la información: ideas incompletas o subdesarrolladas, varias ideas en un párrafo, problemas de concordancia, relación entre las ideas del párrafos, relación entre párrafos, empleo de información irrelevante, problemas de ubicación jerárquica de las ideas , repeticiones innecesarias de palabras, frases e ideas, léxico inadecuado al tema, contexto comunicativo, tipo de receptor e intenciones del autor, falta de claridad en las ideas y problemas de coherencia global.

10.2 Cuarenta y ocho (48) textos, equivalentes a más de la mitad de la muestra selecciona$\mathrm{da}$, contienen ideas incompletas o subdesarrolladas, lo cual propicia que el receptor tenga que apoyarse en otras informaciones, y realizar ingentes esfuerzos para poder construir los significados. Además, demuestra que los estudiantes no están conscientes de la necesidad de expresar sus ideas de forma completa y clara para poder cumplir con los objetivos propuestos. La dificultad antes mencionada, se mantuvo en el primer texto elaborado, pero se superó paulatinamente en el segundo y tercero, mediante la puesta en práctica de algunas estrategias metodológicas, durante el desarrollo del proyecto.

10.3 Las variables: varias ideas en un párrafo, relación entre las ideas del mismo y entre párrafos, en los escritos de los estudiantes alcanzaron porcentajes altos, 32\%, 25\% y $20 \%$ respectivamente, lo que significa que deben ser tomadas en cuenta en la enseñanza de la expresión escrita, específicamente en la propiedad textual, coherencia: calidad de la información. Esta deficiencia no tuvo mayor incidencia en la escritura de los textos expositivos realizados posteriormente.

10.4 Otro dato significativo reflejado en el gráfico $\mathrm{N}^{\circ} 4$ es el problema de concordancia, identificado en el $45 \%$ de los textos elaborados por los estudiantes. Es importante señalar que esto refleja falta de relación entre los diferentes elementos gramaticales que conforman el entretejido de relaciones morfológicas en el discurso, lo que origina falta de calidad en las ideas expuestas. Las dificultades de este tipo fueron muy notorios en el primero y segundo texto, las que fueron mejoradas, en alguna medida, en el último escrito, situación que es imposible erradicar en un semestre.

10.5 De ochenta y cuatro (84) estudiantes de los grupos A, B Y C, cincuenta y uno (51) equivalente al $61 \%$, repitieron palabras, frases e ideas en sus escritos, lo cual evidencia un discurso reiterativo, pobreza léxica, falta de dominio del tema y capacidad verbal, aspectos que afectan la calidad del texto, debilitan el estilo y por ende la comprensión global. A pesar de que en los escritos diagnósticos se dieron problemas de este tipo, con la puesta en práctica del proyecto didáctico, los estudiantes manifestaron un avance significativo de esta dificultad. 


\section{Conclusiones}

10.6 La variable léxico inadecuado al tema, contexto comunicativo tipo de receptor e intenciones del autor, representado con un $44 \%$, muestra inconsistencia en el contenido de las ideas, debido a la imprecisión y ambiqüedad de los términos utilizados. Con la ayuda de recursos de apoyo como: diccionarios, gramáticas, material bibliográfico sobre el tema, y con el empleo de algunas estrategias didácticas, los estudiantes lograron usar con mayor precisión el vocabulario, durante la elaboración del texto final.

10.7 La falta de claridad en las ideas, lo mismo que los problemas de coherencia global en los textos diagnósticos, alcanzaron un alto porcentaje en los tres grupos, $52 \%$ y $51 \%$ respectivamente. Lo anterior demuestra que es imposible separar estos dos aspectos, de las variables en estudio: Ideas incompletas o subdesarrolladas y Léxico inadecuado al tema, contexto comunicativo, tipo de receptor e intenciones del autor. Para lograr la coherencia, es decir la unidad de un texto es necesario

tomar en cuenta una serie de elementos de origen textual y contextual. En el primer texto elaborado por los estudiantes durante el proyecto se dieron problemas de este tipo, los cuales fueron superados en el segundo y tercero.

10.8 Los resultados de la diagnosis constituyeron puntos relevantes de referencia para poder diseñar algunas estrategias didácticas que incidieran positivamente en la superación de las principales dificultades detectadas en los escritos de los estudiantes, y de esta manera contribuir al desarrollo de la competencia comunicativa.

10.9 Todos los participantes en el proyecto valoraron la importancia de la planificación, previa e la elaboración del texto, como guía indispensable para visualizar al destinatario, definir los objetivos y jerarquizar ideas. Además la revisión constante entre iguales, las sugerencias de los docentes involucrados en la tarea y las correcciones realizadas, contribuyeron a la realización de un texto más coherente, recursos valiosos para que los docentes enseñemos la lengua española de manera funcional y comunicativa.

10.10 Es necesario aclarar que entre los textos diagnósticos elaborados por los estudiantes de los cursos regulares y los de profesionalización no existen diferencias significativas, a pesar de que los últimos se desempeñan como maestro/as, y es lógico deducir que éstos deberían presentar menos dificultades en sus escritos, por la labor que desempeñan como formadores.

10.11 Todos /as los /as involucrados/as en esta experiencia afirmaron que los objetivos se cumplieron en un $93 \%$, y que éstos guiaron cada una de las diversas fases del mismo. 


\section{- Recomendaciones}

A partir de los resultados del trabajo de investigación y con el propósito de mejorar el proceso enseñanza-aprendizaje de la expresión escrita para la redacción de textos expositivos, se recomienda a los docentes y otras personas interesadas en la renovación de la práctica pedagógica, lo siguiente:

11.1. Prestar mayor atención a la aplicación y análisis de las pruebas diagnósticas, porque permite enfocar la enseñanza hacia los principales problemas que presentan los estudiantes y ayuda a reflexionar sobre los mismos y buscar soluciones que favorezcan la calidad de los textos.

11.2. En el proceso de revisión de los trabajos elaborados por los estudiantes, los docentes deben prestar una mayor atención a la coherencia textual: repetición de palabras, frases e ideas, ideas incompletas o subdesarrolladas, falta de claridad en las ideas y problemas de coherencia global, léxico inadecuado al tema, contexto comunicativo, tipo de receptor e intenciones del autor y problemas de concordancia.

11.3. Promover cursos de actualización a los docentes de los diferentes niveles de educación sobre la coherencia textual para mejorar la enseñanza aprendizaje de la expresión escrita.

11.4. Impulsar actividades lógicas y secuenciadas durante la enseñanza de la expresión escrita que consideren la planificación, textualización, revisión y corrección, enfatizando más en el proceso que en el producto final.

11.5. Enfatizar durante el proceso aprendizaje de la expresión escrita la elaboración, revisión y corrección de bosquejos, previo a la fase de textualización, ya que permite a los alumnos organizar las ideas, seguir un orden lógico y abordar los aspectos relevantes del texto.

11.6. Concientizar a los docentes de la importancia del estudio teórico y práctico de las tipologías textuales, específicamente del texto expositivo, por ser el más empleado en las comunicaciones cotidianas.

11.7. Implementar el trabajo cooperativo como una práctica sistemática, en el proceso de enseñanza de la expresión escrita en todos los niveles de educación.

11.8. Incentivar a los docentes y estudiantes de la carrera de Lengua y Literatura en la realización de trabajos que profundicen en la línea de investigación, didáctica con el fin de contribuir a mejorar el proceso enseñanza aprendizaje de la lengua.

11.9. Reducir el número de estudiantes de los grupos, a fin de garantizar la calidad de la enseñanza de la expresión escrita y hacer énfasis en el carácter procedimental que tiene este aspecto de la lengua.

11.10. Implementar este tipo de propuestas, tanto a nivel universitario como en las escuelas primarias y secundarias, ya que a través de ellas se desarrollan las macrohabilidades del lenguaje: leer, escribir, hablar y escuchar, indispensables para una efectiva comunicación. 


\section{REFERENCIAS}

Aznar y Cross. (1993). Lectura y coherencia textual (análisis de un texto narrativo) Comunicación y Lenguaje. $\mathrm{N}^{\circ} .17$ pp. $16-28$.

Aznar, E. y otros (1991). Coherencia textual y lectura. Barcelona: Horsori

Aznar, E., Cros, A. y Quintana, H. (1991). Coherencia Textual y Lectura. Barcelona: Horsori .

Boix, A. y otros. ( 1994 ). La expresión escrita. Barcelona: TEIDE.

Bustos, G. (1996). La construcción de textos en Español, España: Varona.

Camps, A. y Castellón, M.( s.f ) (en prensa). Las Estrategias de Enseñanza y Aprendizaje en el proceso de Composición Escrita. Monereo C. y Solé I. (eds.). El asesoramiento psicopedagógico: una perspectiva profesional. Madrid: Alianza.

Camps, A. (1990). Modelos del proceso de redacción: algunas implicaciones para la enseñanza. Infancia y Aprendizaje $\mathrm{N}^{\circ} 49$. pp. 3 - 17.

Cassany, D. (1993 ). Describir el escribir. Barcelona: Paidós.

Cassany, D. (1994). Enseñar lengua. Barcelona: Graó.

Colomer T, Rivas T. y Utset, M. 1993. La Escritura por proyectos: Tú eres el autor. Aula de Innovación Educativa N ${ }^{\circ} .14$ pp. -28.

Colomer, T. (1997). "La enseñanza y aprendizaje de la expresión escrita”. Signos N 20 p.6.

Graves, D. 1987). Didáctica de la escritura, Madrid: Ministerio de Educación y ciencia.

Herrera, M.E. (Coord.). (1999) ¿ redactar ! México: Patria.

Kaifer, A. (1992). El análisis de textos escritos producidos en la escuela. Aula de Innovación $\mathbf{N}^{\circ} .2$ pp. 29-31.

Del Río, M.A. (1995). Taller de Redacción 1. México: Fuentes Impresores, S.A.

Lomas, C y Osoro, A. ( 1994 ). El Enfoque Comunicativo de la enseñanza de Lengua. Barcelona: Piados.

Martínez R. ( 1997 ). Conectando Textos. Barcelona: OCTAEDRO. 